\title{
IMPACTO TÉCNICO E ECONÔMICO DAS PERDAS DE SOLO E NUTRIENTES POR EROSÃO NO CULTIVO DA CANA-DE-AÇÚCAR ${ }^{1}$
}

\author{
NILO S. F. DE ANDRADE ${ }^{2}$, MARCILIO V. MARTINS FILHO ${ }^{3}$, JOSÉ L. R. TORRES ${ }^{4}$, \\ GENER T. PEREIRA ${ }^{5}$, JOSÉ MARQUES JÚNIOR
}

\begin{abstract}
RESUMO: O objetivo geral foi demonstrar o impacto técnico e econômico das perdas de solo e nutrientes por erosão no cultivo da cana-de-açúcar. Propôs-se avaliar as perdas de nutrientes por erosão ( $\mathrm{P}, \mathrm{K}, \mathrm{Ca}$ e $\mathrm{Mg}$ ), o custo de reposição de nutrientes e o de produção da cana em dois sistemas de colheita (cana crua e queimada) em Catanduva - SP, em área de 100 ha para cada sistema, formadas e colhidas no mesmo período (2002 a 2007), com similaridade quanto ao tipo de solo, variedade, topografia e numero de cortes. A metodologia baseou-se na equação universal da perda de solos e teoria dos custos de produção e de reposição de nutrientes. A maior perda de solo e de nutrientes por erosão ocorreu nas áreas de cana queimada; a cana queimada (corte manual), na média dos cinco cortes, perde $48,82 \%$ por hectare a mais de solo, $56,45 \%$ de potássio $(\mathrm{K})$ e 60,78 $\%$ de fósforo (P) do que a cana crua (corte mecanizado); o custo de reposição de nutrientes, em média, na cana queimada ( $\mathrm{R} \$ 33,92 \mathrm{ha}^{-1} \mathrm{ano}^{-1}$ ), foi superior ao da cana crua ( $\left.\mathrm{R} \$ 21,12 \mathrm{ha}^{-1} \mathrm{ano}^{-1}\right)$; a cana crua apresentou menor custo de produção $\left(\mathrm{R} \$ 29,60 \mathrm{Mg}^{-1}\right)$ quando comparado à cana queimada $\left(\mathrm{R} \$ 32,71 \mathrm{Mg}^{-1}\right)$; a cana crua apresentou maior retorno médio $\left(\mathrm{R} \$ 5,70 \mathrm{Mg}^{-1} \mathrm{ano}^{-1}\right)$ com relação à cana queimada $\left(\mathrm{R} \$ 2,59 \mathrm{Mg}^{-1}\right)$.
\end{abstract}

PALAVRAS-CHAVE: sistemas de colheita, erosão do solo, retorno técnico e econômico.

\section{ECONOMIC AND TECHNICAL IMPACT IN SOIL AND NUTRIENT LOSS THROUGH EROSION IN THE CULTIVATION OF SUGAR CANE ${ }^{1}$}

\begin{abstract}
The general objective was to show the economic and technical impact in soil and nutrient loss through erosion in the cultivation of sugar cane. It was specifically to evaluate the nutrient loss through erosion $(\mathrm{P}, \mathrm{K}, \mathrm{Ca}$ and $\mathrm{Mg}$ ), the cost of replacing the nutrients and the production of sugar cane in two harvesting systems (raw and burned sugar cane) in Catanduva, state of São Paulo, Brazil. An area of 100 ha was studied for each system, formed and harvested in the same period (2002 and 2007), with similarities in the type of soil, variety, topography, and the number of cuts. The methodology was based on the universal equation of soil loss and the theory of production costs and the replacement of nutrients. The greatest loss of soil nutrients and erosion occurred in the areas of the burned sugar cane; the burned sugar cane (cut by hand), the average of five cuts, losses $48.82 \%$ per hectare of land, $56.45 \%$ of potassium $(\mathrm{K})$ and $60.78 \%$ of phosphorus (P) than the raw sugarcane (mechanical harvesting), the replacement cost of nutrients, on average, by the burned cane ( $\mathrm{R} \$ 33.92 \mathrm{ha}^{-1}$ year $^{-1}$ ) was higher that the raw sugarcane $\left(\mathrm{R} \$ 21.12 \mathrm{ha}^{-1}\right.$ year $\left.{ }^{-1}\right)$, the raw sugar cane had lower production cost $\left(\mathrm{R} \$ 29.60 \mathrm{Mg}^{-1}\right)$ compared to the burned sugar cane $\left(\mathrm{R} \$ 32.71 \mathrm{Mg}^{-1}\right)$; the raw sugar cane had a higher average return $\left(\mathrm{R} \$ 5.70 \mathrm{Mg}^{-1}\right.$ year $\left.{ }^{-1}\right)$ with respect to the burned sugar cane $\left(\mathrm{R} \$ 2.59 \mathrm{Mg}^{-1}\right)$.
\end{abstract}

KEYWORDS: harvesting systems, soil erosion, technical and economic erosion.

\footnotetext{
${ }^{1}$ Parte da tese de Doutorado do primeiro autor.

${ }^{2}$ Prof. Doutor em Ciência do Solo do Instituto Federal do Triângulo Mineiro (IFTM), Câmpus Uberaba, nilo@iftm.edu.br.

${ }^{3}$ Prof. Adjunto, Departamento de Solos e Adubos, UNESP, Jaboticabal - SP, mfilho@ fcav.unesp.br

${ }^{4}$ Prof. Doutor em Produção Vegetal do IFTM, Câmpus Uberaba, jlrtorres@iftm.edu.br.

${ }^{5}$ Prof. Adjunto, Departamento de Ciências Exatas, UNESP, Jaboticabal - SP, genertp@ @cav.unesp.br.

${ }^{6}$ Prof. Adjunto, Departamento de Solos e Adubos, UNESP, Jaboticabal - SP, marques@ fcav.unesp.br.

Recebido pelo Conselho Editorial em: 5-11-2009

Aprovado pelo Conselho Editorial em: 13-4-2011
} 


\section{INTRODUÇÃO}

A cultura da cana-de-açúcar ocupa posição de destaque no Brasil por ser uma cultura que, além de alto retorno econômico, pode ser usada tanto pela indústria alimentar quanto como fonte alternativa de energia, e ainda tem grande importância social pela mão de obra empregada. O Brasil é o maior produtor de cana-de-açúcar do mundo, atingindo uma área total cultivada de 6,2 milhões de hectares, com produção anual da ordem de 493 milhões de megagramas (Mg) (FATOR BRASIL, 2009). No Brasil, os estados que apresentam as maiores produções de cana são, em ordem de classificação, São Paulo, Paraná e Alagoas UDOP (2007).

Com a adoção da tecnologia "flex-fuel", a partir de 2003, aliada as perspectivas de aumento das exportações de etanol, o álcool passou a ser o principal fator estratégico para a ampliação e consolidação do setor sucroalcooleiro. É preciso considerar o fato de que um avanço da área de produção de cana-de-açúcar, estimulado pela produção de álcool e açúcar, pode provocar uma pressão em regiões mais sensíveis ambiental e socialmente (TORQUATO et al., 2009). MARTINS FILHO et al. (2009) demonstraram tal preocupação, sob o ponto de vista da conservação do solo e da água, com a expansão das áreas de produção de cana-de-açúcar no interior paulista, principalmente em solos suscetíveis à erosão como os Argissolos. Na safra de 2008/2009, os canaviais paulistas ocupavam cerca de $24,0 \%$ da área de uso agrícola do Estado.

$\mathrm{Na}$ unidade sucroalcooleira pesquisada, a produção de cana crua devido à colheita mecanizada ganhou espaço no setor canavieiro paulista, com o benefício de promover a cobertura do solo com resíduos da cultura de cana-de-açúcar. Tal sistema de manejo é importante, principalmente em solos suscetíveis à erosão, a exemplo dos Argissolos que ocorrem em extensas áreas do Estado de São Paulo. Com a manutenção dos resíduos vegetais na superfície do solo, estes poderão interceptar as gotas de chuva e dissipar sua energia, evitando a desagregação das partículas e a formação do selamento superficial, e, consequentemente, reduzir ou mitigar os efeitos adversos da erosão.

Da área colhida nos canaviais paulistas, 50,9\% produzem cana queimada, ou seja, aquela que utiliza a colheita manual. Neste sistema de produção, há eliminação do palhiço pelo fogo, o que implica redução da cobertura vegetal oferecida ao solo. Ademais, atualmente, o processo de colheita da cana vem sofrendo, também, modificações em função da entrada em foco do aproveitamento do palhiço para aplicações não consolidadas ainda comercialmente, tais como geração de energia e cobertura vegetal para agricultura convencional ou orgânica (BRAUNBECK \& OLIVEIRA, 2006). Tais aspectos têm efeito pronunciado no processo de erosão do solo e nas perdas de nutrientes associadas a este fenômeno, como apontam trabalhos de SOUZA et al. (2005), IZIDORIO et al. (2005) e MARTINS FILHO et al. (2009).

A análise das consequências do cultivo de cana crua e da queimada, sob o ponto de vista econômico, não tem sido conduzida no sentido de valorar questões relativas ao manejo e à conservação do solo, principalmente quanto às perdas de nutrientes por erosão nos custos de produção da cana nos dois sistemas mencionados. Daí a importância de que pesquisas com tal intuito sejam conduzidas, como a proposta no presente trabalho.

O objetivo deste trabalho foi demonstrar os impactos técnico e econômico das perdas de solo e nutrientes por erosão no cultivo da cana-de-açúcar, considerando-se os sistemas de cana crua (colheita mecanizada) e cana queimada (colheita manual).

\section{MATERIAL E MÉTODOS}

O presente estudo foi desenvolvido em área de um empreendimento sucroalcooleiro localizada no município de Catanduva, noroeste do Estado de São Paulo (latitude $21^{\circ} 05^{\prime} \mathrm{S}$ e longitude $49^{\circ} 01^{\prime}$ W). O clima, segundo a classificação de Köeppen, é o denominado de clima tropical quente úmido, tipo Aw, seco no inverno, com precipitação média anual de $1.350 \mathrm{~mm}$. A área apresenta um histórico de mais de 20 anos consecutivos com cultivo de cana-de-açúcar. O solo da área foi classificado como Argissolo Vermelho-Amarelo eutrófico (EMBRAPA, 1999). 
$\mathrm{Na}$ área do empreendimento sucroalcooleiro, dois cenários de produção de cana-de-açúcar foram avaliados: 1) 100 ha no sistema de produção de cana crua (colheita mecânica); 2) 100 ha no sistema de produção de cana queimada (colheita manual). Desta forma, para a realização da pesquisa, foram considerados, tanto para o cultivo da cana crua quanto para o da cana queimada, $o$ mesmo tipo de solo, topografia semelhante com declividade média em torno de $0,052 \mathrm{~mm}^{-1} \mathrm{e}$ formato convexo, os mesmos ciclos produtivos, a mesma variedade de cana (SP - 3250) e tratos culturais semelhantes, com diferenças apenas quanto ao fato de a cana ser colhida mecanicamente (cana crua) ou manualmente (cana queimada).

Em cada um dos dois cenários, foram considerados 100 pontos georreferenciados, nos quais amostras de solo foram coletadas para fins de análises físicas e químicas por SANCHEZ (2003). A partir de tais análises, considerando-se resultados de pesquisas desenvolvidas por AMARAL (2003), LICCIOTI (2004), MARTINS FILHO (2007a) e MARTINS FILHO et al. (2009), na área, estimaram-se as perdas de solo e nutrientes por erosão para os dois cenários. A erosão foi estimada como proposto por WISCHMEIER \& SMITH (1978), por meio da eq.(1):

$$
\mathrm{A}=\mathrm{R} \text { K LS C P }
$$

em que,

A - perda de solo por unidade de área, $\mathrm{Mg} \mathrm{ha}^{-1} \mathrm{ano}^{-1}$;

$\mathrm{R}$ - fator de erosividade da chuva, $\mathrm{MJ} \mathrm{mm} \mathrm{ha}{ }^{-1} \mathrm{~h}^{-1}$;

$\mathrm{K}$ - fator de erodibilidade do solo, $\mathrm{Mg} \mathrm{ha}^{-1} \mathrm{MJ}^{-1} \mathrm{~mm}^{-1}$ ha h;

LS - fator para o efeito combinado do declive e do comprimento da rampa;

$\mathrm{C}$ - fator cobertura e manejo do solo, e

$\mathrm{P}$ - fator práticas conservacionistas.

A erosividade média das chuvas (R) foi estimada em 7540, $901 \mathrm{MJ} \mathrm{mm} \mathrm{ha}^{-1} \mathrm{~h}^{-1}$ ano $^{-1}$, através de método proposto por LOMBARDI NETO et al. (2000). O fator erodibilidade (K) foi estimado utilizando a eq.(2), proposta por DENARDIN (1990):

$$
\mathrm{K}=0,00000748 \mathrm{M}+0,004448059 \mathrm{p}-0,06631175 \mathrm{DMP}+0,01039567 \mathrm{X} 32
$$
em que,

M - novo silte (novo silte + nova areia);

p - permeabilidade codificada segundo WISCHMEIER et al. (1971);

DMP - diâmetro médio ponderado das partículas do solo inferiores a 2,00 mm;

$\mathrm{X} 32$ - nova areia $(\mathrm{MO} / 100)$; Novo silte - silte + areia muito fina;

$\%$; Nova areia $=$ areia muito grossa + areia grossa + areia média + areia fina, $(\%)$.

$\mathrm{O}$ valor médio do fator $\mathrm{K}$ estimado foi de $0 ; 024 \mathrm{Mg} \mathrm{ha}^{-1} \mathrm{MJ}^{-1} \mathrm{~mm}^{-1}$ ha $\mathrm{h}$, o qual não diferiu significativamente, pelo teste $\mathrm{t}$, daquele determinado por AMARAL (2003) e igual a 0;023 $\mathrm{Mg} \mathrm{ha}^{-1}$ $\mathrm{MJ}^{-1} \mathrm{~mm}^{-1}$ ha h, para o mesmo Argissolo do presente trabalho. O fator LS foi determinado como proposto por WISCHMEIER \& SMITH (1978), por meio da eq.(3):

$$
\mathrm{LS}=(\lambda / 22,13)^{\mathrm{m}}\left(65,41 \operatorname{sen}^{2} \theta+4,56 \operatorname{sen} \theta+0,065\right)
$$

em que,

$\lambda$ - comprimento de rampa, $\mathrm{m}$;

$\mathrm{m}$ - expoente variável com a declividade do terreno, e

$\theta$ - ângulo do declive em graus.

$\mathrm{O}$ fator $\mathrm{C}$ foi determinado considerando-se razões de perdas de solo por erosão apresentadas por AMARAL (2003) e SERRA (2004) e, ainda, a distribuição da erosividade das chuvas durante as safras de 2002/2003 a 2006/2007. Os procedimentos para a determinação do fator C foram os mesmos adotados por SERRA (2004). Neste trabalho, os valores de C estabelecidos e utilizados foram: 1) cana queimada - 0,16 ( $1^{\circ}$ corte); 0,13 ( $2^{-}$corte); 0,16 ( $3^{\circ}$ corte); 0,13 ( $4^{\circ}$ corte); 0,13 ( $5^{\circ}$ 
corte) e 2$)$ cana crua - 0,16 ( $1^{\underline{\mathrm{o}}}$ corte); 0,10 ( $2^{\mathrm{o}}$ corte); 0,09 ( $3^{\mathrm{o}}$ corte); 0,07 ( $4^{\underline{\mathrm{o}}}$ corte); 0,06 ( $5^{\underline{\mathrm{o}}}$ corte). Para o fator P, adotaram-se valores propostos por WISCHMEIER \& SMITH (1978), em função da declividade do terreno. A tolerância de perdas de solo por erosão (T) foi determinada a partir de atributos do solo, conforme método proposto por OLIVEIRA (2004), e estabelecida como sendo igual a $5,1 \mathrm{Mg} \mathrm{ha}^{-1}$ ano $^{-1}$.

Os valores de perdas de solo por erosão foram submetidos ao teste $\mathrm{F}$ da análise da variância, e as médias foram confrontadas pelo teste de comparações múltiplas de Tukey, a 5\% de probabilidade. Para todas as análises estatísticas, foi utilizado o programa Statistica (STATSOFT, 1994).

Análises de regressão foram conduzidas entre os dados de perdas de nutrientes e solo por erosão, os quais foram obtidos por AMARAL (2003) e LICCIOTI (2004). Os modelos ajustados foram utilizados em estimativas das perdas de nutrientes (PN) por erosão, para fins de valoração econômica destas perdas, por meio das eqs.(4); (5); (6) e (7):

$$
\begin{array}{ll}
\mathrm{PN}_{\mathrm{P}}=22,844+28,098 \log (\mathrm{A}) & \mathrm{R}^{2}=0,86 * * \\
\mathrm{PN}_{\mathrm{K}}=2,360+1,184 \log (\mathrm{A}) & \mathrm{R}^{2}=0,83^{* *} \\
\mathrm{PN}_{\mathrm{Ca}}=46,174+45,434 \log (\mathrm{A}) & \mathrm{R}^{2}=0,97 * * \\
\mathrm{PN}_{\mathrm{Mg}}=15,149+15,714 \log (\mathrm{A}) & \mathrm{R}^{2}=0,93 * *
\end{array}
$$

em que,

$\mathrm{PN}_{\mathrm{P}}$ - perdas de fósforo, $\mathrm{mg} \mathrm{dm}^{-3}$;

$\mathrm{PN}_{\mathrm{K}}$ - perdas de potássio, $\mathrm{mmol}_{\mathrm{c}} \mathrm{dm}^{-3}$;

$\mathrm{PN}_{\mathrm{Ca}}$ - perda de cálcio, $\mathrm{mmol}_{\mathrm{c}} \mathrm{dm}^{-3}$, e

$\mathrm{PN}_{\mathrm{Mg}}$ - perda de magnésio, $\mathrm{mmol}_{\mathrm{c}} \mathrm{dm}^{-3}$.

O custo de reposição dos nutrientes perdidos $(\mathrm{CR})$, no processo produtivo da cana-de-açúcar, foi tomado como uma medida do custo interno da erosão do solo na área cultivada e estabelecido utilizando-se da seguinte eq.(8), descrita por MARQUES (1998) como:

$$
\mathrm{CI}=\mathrm{Q}_{\mathrm{n}}\left(\mathrm{P}_{\mathrm{n}}+\mathrm{C}_{\mathrm{a}}\right)
$$

em que,

CI - custos internos da erosão, $\mathrm{R} \$ \mathrm{ha}^{-1} \mathrm{ano}^{-1}$;

$\mathrm{Q}_{\mathrm{n}}$ - fertilizantes carreados pela erosão, $\mathrm{kg} \mathrm{ha}^{-1} \mathrm{ano}^{-1}$;

$\mathrm{P}_{\mathrm{n}}$ - preço dos fertilizantes, $\mathrm{R} \$ \mathrm{~kg}^{-1}$, e

$\mathrm{C}_{\mathrm{a}}$ - custo de aplicação dos fertilizantes, $\mathrm{R} \$ \mathrm{~kg}^{-1}$.

Para aplicação da eq.(8), nas safras de 2002/2003 a 2006/2007, utilizaram-se as perdas de solo por erosão obtidas com a eq.(1), para os 100 pontos amostrados em cada uma das áreas com cana crua e cana queimada.

Como o custo de aplicação foi incluso no preço do fertilizante, a expressão $(\mathrm{Pn}+\mathrm{Ca})$ ficou designada apenas Pn, gerando, portanto, a seguinte eq.(9):

$$
\mathrm{CR}=\sum_{\mathrm{i}=1}^{\mathrm{n}} \mathrm{P}_{\mathrm{n}} \mathrm{Q}_{\mathrm{n}}
$$

em que,

$\mathrm{CR}$ - custos de reposição, $\mathrm{R} \$ \mathrm{ha}^{-1} \mathrm{ano}^{-1}$;

Pn - preço dos fertilizantes (incluindo o preço de aplicação do fertilizante), $R \$ \mathrm{~kg}^{-1}$, e

Qn - quantidade de fertilizantes, $\mathrm{kg} \mathrm{ha}^{-1} \mathrm{ano}^{-1}$.

Obs: os custos e os preços foram corrigidos pelo IGP - FGV.

A determinação e a análise dos custos de produção foram realizadas com base em todas as despesas envolvidas na produção da cana crua e da cana queimada, no período de um corte ao 
outro, até terminar a vida útil do canavial, acrescido de seus custos de oportunidades e depreciações (PEREIRA et al., 2007). Ainda segundo o autor, as depreciações lineares constituem um método de quantificar o custo de reposição de bens duradouros devido ao desgaste pelo uso, e função do valor atual e da vida útil restante ou do valor inicial do bem e da vida útil total nos diversos períodos em que são utilizados.

Para o cálculo da depreciação anual do canavial por hectare (cana crua e/ou queimada), utilizou-se a eq.(10):

$$
\mathrm{D}_{\mathrm{L}}=\frac{(\mathrm{VN}-\mathrm{VR})}{\sum_{\mathrm{i}=\mathrm{n}}^{\mathrm{n}} \text { PROD }_{\mathrm{i}}} \text { PROD }_{\mathrm{j}}
$$

em que,

$\mathrm{D}_{\mathrm{L}}$ - depreciação anual da lavoura de cana por hectare, $\mathrm{R} \$ \mathrm{ha}^{-1} \mathrm{ano}^{-1}$;

$\mathrm{VN}$ - valor de formação da lavoura por hectare, $\mathrm{R} \$ \mathrm{ha}^{-1}$;

VR - valor residual da lavoura por hectare, $\mathrm{R} \$ \mathrm{ha}^{-1}$;

PROD $_{\mathrm{i}}$ - produtividade da cana em cada um dos cinco cortes, $\mathrm{Mg} \mathrm{ha}^{-1}$, e

$\mathrm{PROD}_{\mathrm{j}}$ - produtividade da cana no ano (j) onde se quer determinar a depreciação, $\mathrm{Mg} \mathrm{ha}^{-1}$.

Obs: O valor residual da lavoura foi considerado igual a zero.

Para o cálculo da depreciação anual das benfeitorias por hectare (cana crua e/ou queimada), utilizou-se a eq.(11):

$$
\mathrm{D}_{\mathrm{b}}=\left[(\mathrm{VN}-\mathrm{VR}) / \mathrm{VU}_{\mathrm{a}}\right] \times\left(\mathrm{T}_{\mathrm{o}} / \mathrm{A}_{\mathrm{c}}\right)
$$

em que,

$\mathrm{D}_{\mathrm{b}}$ - depreciação anual das benfeitorias por hectare, $\mathrm{R} \$ \mathrm{ha}^{-1} \mathrm{ano}^{-1}$;

$\mathrm{VN}$ - valor inicial do recurso, $\mathrm{R} \$$

VR - valor residual do recurso, $\mathrm{R} \$$;

$\mathrm{VU}_{\mathrm{a}}$ - vida útil, anos;

$\mathrm{T}_{\mathrm{o}}$ - taxa de ocupação do bem pela lavoura, \%, e

$\mathrm{A}_{\mathrm{c}}$ - área com cana, 100 ha.

Para o cálculo da depreciação anual das máquinas e equipamentos por hectare de cana, utlizou-se a eq.(12):

$$
\mathrm{D}_{\mathrm{me}}=\left[(\mathrm{VN}-\mathrm{VR}) / \mathrm{VU}_{\mathrm{h}}\right] \times \mathrm{HT}_{\mathrm{r}}
$$

em que,

$\mathrm{D}_{\mathrm{me}}$ - depreciação de máquinas e equipamentos por hectare no ano, $\mathrm{R} \$ \mathrm{ha}^{-1} \mathrm{ano}^{-1}$;

$\mathrm{VN}$ - valor inicial do recurso, $\mathrm{R} \$$

VR - valor residual do recurso, $\mathrm{R} \$$;

$\mathrm{VU}_{\mathrm{h}}$ - vida útil do bem definido em horas, h, e

$\mathrm{HT}_{\mathrm{r}}$ - - total de horas trabalhadas por hectare pelo bem no ano, $\mathrm{h} \mathrm{ha}^{-1} \mathrm{ano}^{-1}$.

O custo de oportunidade representa um rendimento que certo recurso, em sua forma física ou monetária estaria rendendo se estivesse sendo aplicado em outra atividade econômica que não aquela na qual esteja sendo aplicado; foi calculado à base da taxa de juros real ao ano (6\% a.a.), valor este aproximado ao rendimento da caderneta de poupança, para cada recurso, exceto terras, cujo custo de oportunidade foi considerado o valor médio de arrendamento de terras na região. Para efeito de cálculos e análises, os custos foram divididos em fixos (despesas na utilização de recursos fixos, tais como: máquinas e equipamentos, benfeitorias, terra, lavoura, impostos e taxas fixas) e variáveis: conservação de máquinas e equipamentos, conservação de benfeitorias, conservação da lavoura, combustíveis, fertilizantes, pesticidas, fungicidas, cupinicidas, formicidas, herbicidas, mão de obra, aluguel de máquinas e equipamentos, Juros sobre custeio e financiamentos, despesas 
gerais. Incluem-se aí seus custos de oportunidade. Por meio das eqs.(13); (14) e (15), determinouse:

$$
\begin{aligned}
& \mathrm{CT}=\mathrm{CFT}+\mathrm{CVT} \\
& \mathrm{CTMe}=\mathrm{CT} / \mathrm{Q} \\
& \mathrm{RMe}=\mathrm{PMe}
\end{aligned}
$$

em que,

CT - custo total, R\$;

CFT - custo fixo total, $\mathrm{R} \$$;

CVT - custo variável total, $\mathrm{R} \$$

$\mathrm{Q}$ - quantidade produzida, T;

CTMe - custo total médio, $\mathrm{R} \$ \mathrm{Mg}^{-1}$, e

$\mathrm{PMe}$ - preço médio por tonelada de cana recebido pelos produtores, $\mathrm{R} \$ \mathrm{Mg}^{-1}$.

\section{RESULTADOS E DISCUSSÃO}

$\mathrm{Na}$ Tabela 1, são apresentados os resultados relativos às perdas estimadas de solo e de nutrientes por erosão do solo, para períodos anteriores a cada corte, nas áreas cultivadas com cana crua e cana queimada, no município de Catanduva-SP, nas safras de 2002/2003 a 2006/2007 ( $1^{\circ}$ ao $5^{\mathrm{o}}$ corte).

Considerando-se que, para o Argissolo das duas áreas, a tolerância de perdas de solo por erosão (T) foi estimada como sendo de $5,1 \mathrm{Mg} \mathrm{ha}^{-1}$ ano $^{-1}$ por AMARAL (2003), é possível verificar que as perdas médias do $1^{\underline{0}}$ ao $5^{-}$corte foram superiores à tolerância, no sistema de cana queimada (Tabela 1). Já para o sistema de cana crua, as perdas de solo por erosão foram inferiores à tolerância do $4^{\underline{0}}$ ao $5^{\underline{0}}$ corte. No início da implantação do sistema de cana crua, as perdas de solo por erosão foram superiores a T. Tal fato pode ser explicado pela ausência até o $2^{\underline{0}}$ corte de cobertura vegetal por resíduos de cana-de-açúcar suficientes e eficientes para controlar a erosão em níveis toleráveis. As perdas de solo por erosões obtidas com a cana crua foram significativamente menores do $2^{-}$ao $5^{\circ}$ corte. Tal resultado confirma observações de MARTINS FILHO et al. (2009), quanto à redução do processo de erosão pelo aumento da percentagem de cobertura oferecida ao solo por resíduos de cana-de-açúcar.

Cumpre observar que, do final do plantio até o primeiro corte, ambos os sistemas (cana crua e cana queimada) apresentaram as mesmas perdas de solo $\left(9,64 \mathrm{Mg} \mathrm{ha}^{-1} \mathrm{ano}^{-1}\right) \mathrm{e}$, consequentemente, as mesmas perdas de nutrientes por erosão: $0,857 \mathrm{Mg} \mathrm{ha}^{-1} \mathrm{ano}^{-1}(\mathrm{P}), 1,268 \mathrm{Mg} \mathrm{ha}^{-1}$ ano $^{-1}(\mathrm{~K}) \mathrm{e}$ 23,767 $\mathrm{Mg} \mathrm{ha}^{-1} \mathrm{ano}^{-1}(\mathrm{Ca}+\mathrm{Mg})$. Isto ocorreu devido ao fato de os sistemas de cana crua e cana queimada terem sido iniciados sob as mesmas condições, ou seja: 1) plantio da cultura na mesma época e classe de solo; 2) uso da mesma variedade de cana; 3) topografia semelhante; 4) tratos culturais iguais, e 5) as mesmas precipitações pluviométricas. Portanto, até o início do primeiro corte, as condições de erosividade, erodibilidade, topografia, cobertura vegetal e manejo do solo e práticas conservacionistas eram semelhantes para os dois sistemas de colheita. Como as amostras de solo foram coletadas pouco antes do início que antecede cada corte, no primeiro corte, a variável queima da cana não havia interferido no processo da perda de solo e nutrientes por erosão, em face de que a queima da palha deixa o solo desnudo e mais exposto às intempéries. Portanto, após o primeiro corte, a cana crua foi acumulando palha, e a cana queimada não; dessa forma, no segundo caso, não contribuiu no controle da erosão. Estes aspectos são coerentes com as observações de BEZERRA \& CANTALICE (2006) e BERTOL et al. (2007), que o aumento da cobertura vegetal contribui no controle do processo de erosão.

AMARAL (2003) estimou perdas por erosão na faixa de $15,6 \mathrm{Mg} \mathrm{ha}^{-1}$ ano $^{-1}$ a 5,6 $\mathrm{Mg} \mathrm{ha}^{-1}$ ano $^{-1}$, para o Argissolo do presente trabalho, considerando cobertura oferecida ao solo no intervalo de $50 \%$ a $100 \%$ por resíduos de cana-de-açúcar. No presente trabalho, as perdas obtidas com cana crua e queimada foram inferiores à média estimada por AMARAL (2003), da ordem de 10,6 $\mathrm{Mg} \mathrm{ha}^{-1}$ 
ano $^{-1}$. MARTINS FILHO et al. (2009) verificaram que há considerável enriquecimento do sedimento erodido por matéria orgânica e nutrientes, se a cobertura do solo por resíduos de cana-de-açúcar sobre a superfície do solo for igual ou inferior a $50 \%$.

TABELA1. Dados de área utilizada, perda de solo e de nutrientes por erosão, obtidos em períodos imediatamente anteriores a cada corte nas áreas cultivadas com cana crua e cana queimada no período: (ano agrícola), (jul./jun.), (2002/2003 a 2006/2007). Data of used area, soil and nutrient erosion, obtained in the periods immediately before each cut in cultivated areas with raw sugarcane and burned sugarcane in the period (season), (Jul / Jun) (2002/2003 to 2006/2007).

\begin{tabular}{|c|c|c|c|c|c|c|}
\hline \multirow{3}{*}{ Ano Agrícola } & \multirow{3}{*}{$\begin{array}{l}\text { Sistemas de } \\
\text { Cultivo }\end{array}$} & \multirow{3}{*}{$\begin{array}{l}\text { Área da } \\
\text { Pesquisa } \\
\text { (ha) }\end{array}$} & \multirow{2}{*}{$\begin{array}{c}\text { Perda de } \\
\text { solo }\end{array}$} & \multicolumn{3}{|c|}{ Perda de Nutrientes por Erosão } \\
\hline & & & & $\mathrm{P}$ & $\mathrm{K}$ & $\mathrm{Ca}+\mathrm{Mg}$ \\
\hline & & & ............... & $\ldots \ldots . . .1$ & ano $\left.^{-1}\right)$. & ........................ \\
\hline \multirow{2}{*}{$\begin{array}{l}1^{\mathrm{o}} \text { corte } \\
2002 / 2003\end{array}$} & Cana crua & 100 & 9.640 & 0,857 & 1,268 & 23,767 \\
\hline & $\begin{array}{l}\text { Cana } \\
\text { queimada }\end{array}$ & 100 & 9.640 & 0,857 & 1,268 & 23,767 \\
\hline \multirow{2}{*}{$\begin{array}{l}2^{-} \text {corte } \\
2003 / 2004\end{array}$} & Cana crua & 100 & 6.691 & 0,544 & 0,834 & 15,204 \\
\hline & $\begin{array}{l}\text { Cana } \\
\text { queimada }\end{array}$ & 100 & 8.336 & 0,716 & 1,074 & 19,912 \\
\hline \multirow{2}{*}{$\begin{array}{l}3^{\underline{0}} \text { corte } \\
2004 / 2005\end{array}$} & Cana crua & 100 & 5.333 & 0,408 & 0,642 & 11,477 \\
\hline & $\begin{array}{l}\text { Cana } \\
\text { queimada }\end{array}$ & 100 & 9.850 & 0,880 & 1,299 & 24,384 \\
\hline \multirow{2}{*}{$\begin{array}{l}4^{\mathrm{o}} \text { corte } \\
2005 / 2006\end{array}$} & Cana crua & 100 & 4.382 & 0,317 & 0,511 & 8,973 \\
\hline & $\begin{array}{l}\text { Cana } \\
\text { queimada }\end{array}$ & 100 & 8.250 & 0,707 & 1,061 & 19,666 \\
\hline \multirow{2}{*}{$\begin{array}{l}5^{-} \text {corte } \\
2006 / 2007\end{array}$} & Cana crua & 100 & 3.666 & 0,251 & 0,415 & 7,162 \\
\hline & $\begin{array}{l}\text { Cana } \\
\text { queimada }\end{array}$ & 100 & 8.137 & 0,695 & 1,044 & 19,331 \\
\hline
\end{tabular}

No sistema de cana queimada do primeiro até o quinto e último corte, ocorreu diminuição nas perdas por erosão da ordem de 15,59\% de solo, 18,90\% de fósforo, 17,66\% de potássio e de 18,66\% para cálcio + magnésio. Contudo, durante todo o ciclo produtivo da cana queimada, as perdas de solo e nutrientes foram elevadas em relação à cana crua, que por sua vez chegou ao último corte com reduções nas perdas por erosão de $61,97 \%$ para solo, $70,71 \%$ para fósforo, $67,27 \%$ para potássio e 69,86\% para cálcio + magnésio, em relação ao primeiro corte. MARTINS FILHO et al. (2009) quantificaram reduções nas perdas de solo por erosão de 62\% a 89\% num Argissolo, com cobertura por resíduos de cana-de-açúcar em superfície de 50\% BEZERRA \& CANTALICE (2006) determinaram reduções no processo de erosão em entressulcos de até $99 \%$, para o efeito conjunto dossel + resíduos de cana-de-açúcar, aos 12 meses de cultivo. De forma global e para todo o ciclo da cultura da cana-de-açúcar crua, no presente trabalho, observou-se diminuição das perdas de solo e nutrientes por erosão do $1^{0}$ ao $5^{\underline{o}}$ corte. Muito provavelmente, no sistema de cana crua, a erosão do solo é reduzida porque há um decréscimo no número de operações de preparo e, também, pela presença de uma camada de resíduos que é deixada sobre a superfície após a colheita, como comprovaram trabalhos de WALTON et al. (2000), BEZERRA \& CANTALICE (2006) e MARTINS FILHO (2007a e b).

Na Tabela 2, consta a média dos resultados técnicos e econômicos das perdas de nutrientes por erosão do solo e seus devidos custos de reposição nos cinco cortes da cana crua e da cana queimada, no município de Catanduva - SP. Através da referida tabela, pode-se observar que a despesa financeira necessária para repor os nutrientes perdidos por erosão do solo levantado pela pesquisa, para cada hectare de cana colhido, é o seguinte: cana crua $\left(21,12 \mathrm{R} \$ \mathrm{ha}^{-1} \mathrm{ano}^{-1}\right)$, sendo que desse total, (2,61 R $\left.\$ \mathrm{ha}^{-1} \mathrm{ano}^{-1}\right)$ foi gasto para repor o fósforo $(\mathrm{P})$ perdido, 1,73 $\mathrm{R} \$ \mathrm{ha}^{-1} \mathrm{ano}^{-1}$ para 
repor o potássio $(\mathrm{K}), 16,78 \mathrm{R} \mathrm{ha}^{-1}$ ano $^{-1}$ para repor o Cálcio $(\mathrm{Ca})$ mais o Magnésio $(\mathrm{Mg})$. Já para a cana queimada, o gasto foi de $\left(33,92 \mathrm{R} \$ \mathrm{ha}^{-1} \mathrm{ano}^{-1}\right)$, sendo que desse total, 4,24 R\$ ha ${ }^{-1}$ ano $^{-1}$ veio da reposição do fósforo $(\mathrm{P}), 2,70 \mathrm{R} \$ \mathrm{ha}^{-1}$ ano $^{-1}$ veio da reposição do potássio $(\mathrm{K}), 26,98 \mathrm{R} \$ \mathrm{ha}^{-1}$ ano $^{-1}$ veio da reposição do Cálcio $(\mathrm{Ca})$ mais o Magnésio $(\mathrm{Mg})$. Na média dos cinco cortes apresentados, a cana crua (corte mecânico) conserva mais as propriedades físicas e químicas do solo, já que a cana queimada (corte manual) perde, em média, dos cinco cortes por hectare, a mais $48,82 \%$ de solo, $56,45 \%$ de potássio $(\mathrm{K})$ e $60,78 \%$ de fósforo $(\mathrm{P})$ do que a cana crua (corte mecanizado). Daí as maiores perdas de solo e, consequentemente, de nutrientes por erosão aconteceram com a cana queimada, que apresentou perdas de solo e de nutrientes superiores aos obtidos no processo da cana crua. Ou seja, a cana crua perdeu, em média, nos cinco cortes: $5.942 \mathrm{~kg} \mathrm{ha}^{-1} \mathrm{ano}^{-1}$ de solo, daí resultou em uma perda média de 13,317 kg/ha/ano de Ca+Mg; $0,734 \mathrm{~kg} \mathrm{ha}^{-1}$ ano $^{-1}$ de K; $0,475 \mathrm{~kg} \mathrm{ha}^{-1}$ ano $^{-1}$ de P. Já a cana queimada perdeu, em média, dos cinco cortes, $8.843 \mathrm{~kg} \mathrm{ha}^{-1}$ ano $^{-1}$ de solo; $21,412 \mathrm{~kg} \mathrm{ha}^{-1}$ ano $^{-1}$ de Ca+Mg; 1,149 kg ha ${ }^{-1}$ ano $^{-1}$ de potássio (K) e $0,771 \mathrm{~kg} \mathrm{ha}^{-1}$ ano $^{-1}$ de fósforo $(\mathrm{P})$.

TABELA 2. Média dos resultados técnicos e econômicos das perdas de nutrientes por erosão, por hectare de solo dos cultivos das canas cruas e queimadas, referentes aos cinco cortes, no período de julho de 2002 a junho de 2007. Average results of technical and economic losses of nutrients per hectare of soil erosion by cultivation of raw and burned sugar cane, for five cuts in the period of July 2002 to June 2007.

\begin{tabular}{|c|c|c|c|c|c|c|c|}
\hline $\begin{array}{l}\text { Sistemas } \\
\text { de } \\
\text { Cultivo }\end{array}$ & $\begin{array}{l}\text { Nutrientes } \\
\text { perdidos } \\
\text { por erosão }\end{array}$ & $\begin{array}{c}\text { Perda de } \\
\text { Nutrientes } \\
\mathrm{kg} \mathrm{ha}^{-1} \text { ano }^{-1}\end{array}$ & $\begin{array}{c}\text { Fertilizante } \\
\text { correspondente }\end{array}$ & $\begin{array}{c}\text { Fertilizante / } \\
\text { Nutriente } \\
\text { kg }\end{array}$ & $\begin{array}{c}\text { Fertilizante } \\
\text { a ser Reposto } \\
\mathrm{kg} \mathrm{ha}^{-1} \text { ano }^{-1}\end{array}$ & $\begin{array}{c}\text { Despesas } \\
\text { com o } \\
\text { Fertilizante } \\
\text { Aplicado } \\
\mathrm{R} \$ \mathrm{~kg}^{-1} \\
\end{array}$ & $\begin{array}{c}\text { Custo de } \\
\text { Reposição } \\
\text { do Nutriente } \\
\text { Perdido (VA) } \\
*_{\mathrm{kg} \mathrm{ha}^{-1} \text { ano }^{-1}}\end{array}$ \\
\hline Cana crua & \multirow[t]{2}{*}{$\mathrm{P}$} & 0,475 & $\begin{array}{l}\text { Superfosfato } \\
\text { simples }\end{array}$ & 5,555 & 2,639 & 0,99 & 2,61 \\
\hline Queimada & & 0,771 & $\left(18 \%\right.$ de $\left.\mathrm{P}_{2} \mathrm{O}_{5}\right)$ & 5,555 & 4,283 & 0,99 & 4,24 \\
\hline Cana crua & \multirow[t]{2}{*}{ K } & 0,734 & $\begin{array}{l}\text { Cloreto de } \\
\text { potássio }\end{array}$ & 1,667 & 1,224 & 1,41 & 1,73 \\
\hline Queimada & & 1,149 & $\left(60 \%\right.$ de $\left.\mathrm{K}_{2} \mathrm{O}\right)$ & 1,667 & 1,915 & 1,41 & 2,70 \\
\hline Cana crua & \multirow[t]{2}{*}{$\mathrm{Ca}+\mathrm{Mg}$} & 13,317 & $\begin{array}{c}\text { Calcário } \\
\text { (32\% de Ca }\end{array}$ & 2,520 & 33,559 & 0,50 & 16,78 \\
\hline Queimada & & 21,412 & $+8 \% \mathrm{Mg})$ & 2,520 & 53,958 & 0,50 & 26,98 \\
\hline \multicolumn{7}{|c|}{ Custo total de reposição de nutrientes da cana crua $\left(\mathrm{R} \$ \mathrm{ha}^{-1} \mathrm{ano}^{-1}\right)$} & 21,12 \\
\hline \multicolumn{7}{|c|}{ Custo total de reposição de nutrientes da cana queimada $\left(\mathrm{R} \$\right.$ ha $^{-1}$ ano $\left.^{-1}\right)$} & 33,92 \\
\hline
\end{tabular}

Nas despesas com o fertilizante aplicado para reposição $\left(\mathrm{R} \$ \mathrm{~kg}^{-1}\right)$, está incluído o seu preço de mercado e o custo na sua aplicação, VA: Valor atual. *Os resultados financeiros da época foram atualizados para agosto de 2007 pelo IGP - FGV.

A cana crua, no primeiro corte, apresentou produtividade de $114,73 \mathrm{Mg} \mathrm{ha}^{-1}$, superior à obtida pela cana queimada $110,50 \mathrm{Mg} \mathrm{ha}^{-1}$ (Tabela 3), o que já era esperado, visto que o efeito da queimada se fez presente diminuindo a produção em 4,23 $\mathrm{Mg} \mathrm{ha}^{-1}$; contudo, do segundo ao quinto corte, a produtividade da cana queimada foi diminuindo ano a ano $(19,24 ; 11,16 ; 8,20$ e $5,86 \mathrm{Mg} \mathrm{ha}^{-1}$, respectivamente), com um grau de variação (queda na produtividade) maior do que a diminuição na produtividade corte a corte da cana crua $\left(8,58 ; 8,03 ; 6,76\right.$ e $8,61 \mathrm{Mg} \mathrm{ha}^{-1}$, respectivamente), chegando ao quinto corte com uma produtividade de $66,04 \mathrm{Mg} \mathrm{ha}^{-1} \mathrm{ano}^{-1}$ e com uma média anual de $83,96 \mathrm{Mg} \mathrm{ha}^{-1}$ ano $^{-1}$ (Tabela 3).

Logo, a cana crua chegou ao quinto corte com produtividade de $82,75 \mathrm{Mg} \mathrm{ha}^{-1}$ e com média anual de 98,75 Mg ha $\mathrm{ano}^{-1}$ (Tabela 3). 
TABELA 3. Produtividades, receitas e custos durante os cinco cortes da vida útil da cana crua (CC) e da cana queimada (CQ). Ano agrícola (julho/junho) de 2002/2003 até (julho/junho) de 2006/2007. Productivity, revenues and expenses during the five cuts of the raw sugarcane (CC) and the burned sugar cane (CQ) in the crop year (July I June) of 2002/2003 until (July / June) of 2006/2007.

\begin{tabular}{|c|c|c|c|c|c|c|c|}
\hline \multirow[b]{2}{*}{ Especificações } & & \multicolumn{6}{|c|}{ Ano Agrícola } \\
\hline & & $\begin{array}{c}1^{\mathrm{o}} \text { corte } \\
(2002 / 03)\end{array}$ & $\begin{array}{c}2^{-} \text {corte } \\
(2003 / 04)\end{array}$ & $\begin{array}{c}3^{\circ} \text { corte } \\
(2004 / 05)\end{array}$ & $\begin{array}{c}4^{-0} \text { corte } \\
(2005 / 06)\end{array}$ & $\begin{array}{c}5^{\mathrm{o}} \text { corte } \\
(2005 / 06)\end{array}$ & $\begin{array}{c}\text { Média } \\
\text { (5 Cortes) }\end{array}$ \\
\hline Custo total (CT) & $\mathrm{CC}$ & $2.916,33$ & $2.827,64$ & $2.991,69$ & $2.963,20$ & $2.885,80$ & $2.916,93$ \\
\hline$\left(\mathrm{R} \$ \mathrm{ha}^{-1}\right)$ & $\mathrm{CQ}$ & $2.975,22$ & $2.725,59$ & $2.542,83$ & $2.627,14$ & $2.542,66$ & $2.678,34$ \\
\hline Custo total médio & $\mathrm{CC}$ & 25,41 & 26,64 & 28,64 & 32,44 & 34,87 & 29,60 \\
\hline $\begin{array}{l}\text { (CTMe) } \\
\mathrm{R} \$ \mathrm{Mg}^{-1}\end{array}$ & CQ & 26,92 & 29,86 & 31,74 & 36,53 & 38,50 & 32,71 \\
\hline Preço médio & $\mathrm{CC}$ & 36,22 & 30,05 & 30,90 & 40,15 & 39,18 & 35,30 \\
\hline $\begin{array}{c}(\mathrm{PMe},) \\
\mathrm{R} \$ \mathrm{Mg}^{-1}\end{array}$ & CQ & 36,22 & 30,05 & 30,90 & 40.15 & 39,18 & 35,30 \\
\hline Receita bruta & $\mathrm{CC}$ & $4.156,13$ & $3.189,69$ & $3.032,38$ & $3.667,93$ & $3.242,15$ & $3.457,66$ \\
\hline$(\mathrm{RB}),\left(\mathrm{R} \$ \mathrm{ha}^{-1}\right)$ & CQ & $4.002,89$ & $2.742,27$ & $2.475,00$ & $2.886,65$ & $2.587,45$ & $2.938,95$ \\
\hline Lucro médio (LMe) & $\mathrm{CC}$ & 10,81 & 3,41 & 2,26 & 7,71 & 4,31 & 5,70 \\
\hline $\mathrm{R} \$ \mathrm{Mg}^{-1}$ & $\mathrm{CQ}$ & 9,30 & 0,19 & $-0,84$ & 3,61 & 0,68 & 2,59 \\
\hline Lucro total & $\mathrm{CC}$ & $1.240,23$ & 361,97 & 221,75 & 704,38 & 356,65 & 562,13 \\
\hline $\begin{array}{c}(\mathrm{LT}) \\
\mathrm{R} \$ \mathrm{ha}^{-1}\end{array}$ & CQ & $1.027,65$ & 17,34 & $-67,28$ & 259,56 & 44,91 & 217,46 \\
\hline Produtividade média & $\mathrm{CC}$ & 114,73 & 106,15 & 98,12 & 91,36 & 82,75 & 98,62 \\
\hline$(\mathrm{Pm}), \mathrm{Mg} \mathrm{ha}^{-1}$ & $\mathrm{CQ}$ & 110,50 & 91,26 & 80,10 & 71,90 & 66,04 & 83,96 \\
\hline
\end{tabular}

CC (Cana crua); CQ (Cana queimada); VA (Valor atual); Custo de formação da lavoura: Cana crua (VA = R $3.351,41$ ha $^{-1}$ ), Cana queimada $\left(\mathrm{VA}=\mathrm{R} \$ 3.390,59,41 \mathrm{ha}^{-1}\right)$. Os valores financeiros da época foram atualizados para agosto de 2007 pelo IGP $-\mathrm{FGV}$.

É possível observar, na Tabela 3, que o custo total médio (CTMe) para se produzir uma tonelada de cana foi menor para a cana crua em todos os cinco cortes. Em média, o CTMe foi de $29,60 \mathrm{R} \$ \mathrm{t}^{-1}$ para cana crua e $32,71 \mathrm{R}^{-1} \mathrm{t}^{-1}$ na cana queimada. Isto resultou em um lucro médio de $5,70 \mathrm{R} \$ \mathrm{t}^{-1}$ para a cana crua e de $2,59 \mathrm{R} \$ \mathrm{t}^{-1}$ para a cana queimada. Portanto, a cana crua apresentou um retorno econômico superior ao da cana queimada, sendo que o empresário deixou de ganhar líquido 3,11 $\mathrm{R} \$ \mathrm{t}^{-1}$ pelo fato de queimar a cana na pré-colheita. Considerando-se, portanto, os valores médios dos cinco cortes, a cana crua apresentou um lucro de 562,13 $\mathrm{R} \$ \mathrm{ha}^{-1}$ ano $^{-1}$ $\left(98,62 \mathrm{Mg} \mathrm{ha}^{-1}\right.$ x 5,70 $\left.\mathrm{R} \$ \mathrm{t}^{-1}\right)$, enquanto a cana queimada apresentou um lucro de 217,46 $\mathrm{R} \$ \mathrm{ha}^{-1}$ ano $^{-1}\left(83,96 \mathrm{Mg} \mathrm{ha}^{-1} \mathrm{ano}^{-1}\right.$ x 2,59 $\left.\mathrm{R} \$ \mathrm{t}^{-1}\right)$. Constata-se, pelos resultados obtidos, que só a diferença entre o lucro com a cana crua e com a cana queimada, que foi de $344,67 \mathrm{R} \$ \mathrm{ha}^{-1} \mathrm{ano}^{-1}$, é superior ao LMe da cana queimada, que foi de $217,46 \mathrm{R} \$ \mathrm{ha}^{-1} \mathrm{ano}^{-1}$.

Na Tabela 3, o lucro médio (LMe) com a cana colhida mecanicamente (cana crua) foi positivo em todos os cortes. O LMe teve o menor valor registrado no terceiro ano de colheita e foi igual a $2,26 \mathrm{R} \$ \mathrm{t}^{-1}$ ou $222,16 \mathrm{R} \$ \mathrm{ha}^{-1}$. Já o maior valor do lucro ocorreu no primeiro corte, que foi de $10,81 \mathrm{R} \$ \mathrm{t}^{-1}$ ou $1.240,44 \mathrm{R} \$ \mathrm{ha}^{-1}$.

O lucro por hectare ou por tonelada de cana colhida manualmente, com a prática da queima da palha antes do corte (cana queimada), foi negativo no terceiro corte, ou seja, apresentou um prejuízo de $0,83 \mathrm{R} \$ \mathrm{t}^{-1}$ ou 99,18 $\mathrm{R} \$ \mathrm{ha}^{-1}$ de cana colhida (Tabela 3). Tal prejuízo ocorreu justamente no ano em que houve a maior perda de solo e de nutrientes na área cultivada com cana queimada. Observa-se, ainda, na Tabela 3, que o maior lucro obtido pela cana queimada foi no primeiro corte e igual a $9,30 \mathrm{R} \$ \mathrm{t}^{-1}$ ou $829,79 \mathrm{R} \$ \mathrm{ha}^{-1}$, valor próximo ao obtido pela cana crua (Tabela 3). Isto ocorreu, principalmente, pelo fato de que, no período antecedente ao primeiro corte, as lavouras de cana crua 
e a queimada estavam em situações semelhantes, quanto às variáveis que influenciam negativamente ou positivamente no processo produtivo de suas lavouras.

O custo de utilização de fertilizantes, no cultivo da cana crua, teve o seu maior valor de $582,84 \mathrm{R} \$ \mathrm{ha}^{-1} \mathrm{ano}^{-1}$ no primeiro corte, a qual decresceu para $459,45 \mathrm{R} \$ \mathrm{ha}^{-1}$ ano ${ }^{-1}$ no segundo corte; daí por diante, foi aumentando corte a corte até o quinto e último $\left(506,20 \mathrm{R} \$ \mathrm{ha}^{-1} \mathrm{ano}^{-1}\right)$. Em média, o custo total de utilização de fertilizantes foi de 504,60 $\mathrm{R} \$ \mathrm{ha}^{-1} \mathrm{ano}^{-1}$. A cana queimada apresentou a mesma tendência da cana crua, quanto aos gastos com fertilizantes, e com os valores bem próximos: $592,67 \mathrm{R} \$ \mathrm{ha}^{-1}$ ano $^{-1}$ no $1^{\mathrm{o}}$ corte, $468,43 \mathrm{R} \$ \mathrm{ha}^{-1}$ ano $^{-1}$ no $2^{\mathrm{o}}$ corte, 477,91 $\mathrm{R} \$ \mathrm{ha}^{-1}$ ano $^{-1}$ no $3^{-}$corte terceiro, 504,61 R $\$$ ha $^{-1}$ ano $^{-1}$ no $4^{\circ}$ corte, $516,01 \mathrm{R} \$$ ha $^{-1}$ ano $^{-1}$ no $5^{\mathrm{o}}$ corte e com uma média anual de 511,93 $\mathrm{R} \$ \mathrm{ha}^{-1} \mathrm{ano}^{-1} \mathrm{com}$ a cana queimada.

A cana queimada apresentou maior custo de produção (CTMe em $\mathrm{R} \$ \mathrm{t}^{-1}$ ) em relação à cana crua, devido principalmente a possuir maior custo de reposição de nutrientes perdidos por erosão do solo (CRN) em todos os cortes e menor produtividade (Tabela 3). Acredita-se que isto ocorra em função do maior processo de erosão ocasionado pela diminuição da cobertura vegetal, diminuição do teor de matéria orgânica e da condutividade hidráulica do solo. Estas argumentações e ilações encontram respaldo em trabalhos desenvolvidos por IZIDORIO et al. (2005), MARTINS FILHO (2007) e MARTINS FILHO et al. (2009).

Uma das variáveis que mais contribuíram para aumentar o lucro da atividade da cana crua é a diminuição da perda de nutrientes, que é um fator muito importante no aumento da produtividade. O contrário acontece com a cana queimada. Isto demonstra que, quando o produtor adota práticas mais sustentáveis de cultivo, o custo com a erosão é menor, como demonstrado por PUGLIESI, (2007) e BERTOL et al., (2007).

\section{CONCLUSÕES}

A maior perda de solo e de nutrientes por erosão ocorreu nas áreas de cana queimada.

A cana queimada (corte manual), na média dos cinco cortes, perde $48,82 \%$ por hectare a mais de solo, $56,45 \%$ de potássio $(\mathrm{K})$ e $60,78 \%$ de fósforo (P) do que a cana crua (corte mecanizado).

$\mathrm{O}$ custo de reposição de nutrientes, em média, na cana queimada $\left(33,92 \mathrm{R} \$ \mathrm{ha}^{-1} \mathrm{ano}^{-1}\right)$, foi superior ao da cana crua $\left(21,12 \mathrm{R} \mathrm{ha}^{-1} \mathrm{ano}^{-1}\right)$.

A cana crua apresentou menor custo de produção $\left(29,60 \mathrm{R} \$ \mathrm{Mg}^{-1}\right)$ quando comparado à cana queimada $\left(32,71 \mathrm{R} \$ \mathrm{Mg}^{-1}\right)$.

A cana crua apresentou maior retorno médio ( $\mathrm{R} \$ 5,70 \mathrm{Mg}^{-1} \mathrm{ano}^{-1}$ ) com relação à cana queimada $\left(\mathrm{R} \$ 2,59 \mathrm{Mg}^{-1}\right)$.

\section{REFERÊNCIAS}

AMARAL, N.S. do. Variabilidade espacial da expectativa e risco de erosão num argissolo sob cultivo de cana-de-açúcar em Catanduva (SP). 2003. 74 f. Monografia (Graduação) - Faculdade de Ciências Agrárias e Veterinárias, Universidade Estadual Paulista.

BERTOL, I.; COGO, N.P.; SCHICK, J.; GUDAGNIN, J.C.; AMARAL, A.J. Aspectos financeiros relacionados às perdas de nutrientes por erosão hídrica em diferentes sistemas de manejo do solo. Revista Brasileira de Ciência do Solo, Viçosa-MG, v.31, n.1, p.133-142, 2007.

BEZERRA, S.A.; CANTALICE, J.R.B. Erosão em sulco em diferentes condições de cobertura do solo, sob cultivo da cana-de-açúcar. Revista Brasileira de Ciência do Solo, Viçosa-MG, v.30, n.3, p.565-573, 2006.

BRAUNBECK, O.A.; OLIVEIRA, J.T.A. Colheita de cana-de-açúcar com auxílio mecânico. Engenharia Agrícola, Jaboticabal, v.26, n.1, p.300-308, 2006. 
DENARDIN, J.E. Erodibilidade do solo estimada por meio de parâmetros físicos e químicos. 1990. 113 f. Tese (Doutorado em Solos e Nutrição de Plantas) - Escola Superior de Agricultura "Luiz de Queiroz", Universidade de São Paulo, Piracicaba, 1990.

EMBRAPA. EMPRESA BRASILEIRA DE PESQUISA AGROPECUÁRIA. Centro Nacional de Pesquisa de Solos (Rio de Janeiro - RJ). Sistema Brasileiro de classificação de solos. Brasília: Embrapa Produção de Informação; Rio de Janeiro: Embrapa Solos, 1999. 412 p.

FATOR BRASIL. São Paulo investe em qualificação para aumentar a produção de cana. 2009. Disponível em: <http://www.revistafatorbrasil.co.br/. Acesso em: 18 jun. 2009.

IZIDORIO, R.; MARTINS FILHO, M.V.; MARQUES JÚNIOR, J.; SOUZA, Z.M.; PEREIRA, G.T. Perdas de nutrientes por erosão e sua distribuição espacial em área sob cana-de-açúcar. Engenharia Agrícola, Jaboticabal, v.25, n.3, p.660-670, 2005.

LICCIOTI, T.T. Perdas de matéria orgânica e nutrientes por erosão num argissolo com resíduos vegetais sobre a superfície em área cultivada com cana-de-açúcar. 2004. 40 f. Monografia (Trabalho de Graduação em Agronomia) - Faculdade de Ciências Agrárias e Veterinárias, Universidade Estadual Paulista, Jaboticabal, 2004.

LOMBARDI NETO, F.; PRUSKI, F.F.; TEIXEIRA, A. de F. Sistema para cálculo da erosividade da chuva para o Estado de São Paulo. Viçosa: Sociedade Brasileira de Ciência do Solo, 2000. 1 CD-ROM.

MARQUES, J.F. Custos da erosão do solo em razão dos seus efeitos internos e externos à área de produção agrícola. Revista de Economia e Sociologia Rural, v.36, n.1, p.61-79, jan./mar., 1998.

MARTINS FILHO, M.V. Modelagem do processo de erosão e padrão espacial da erodibilidade em entressulcos. 2007a. 121 f. Tese (Livre-Docência) - Universidade Estadual Paulista, Faculdade de Ciências Agrárias e Veterinárias, Jaboticabal, 2007.

MARTINS FILHO, M.V. Manejo e conservação do solo em áreas de expansão e renovação de canavial. In: SEGATO, S.V.; FERNANDES, C.; PINTO, A.S. (Org.). Expansão e renovação de canavial, Piracicaba: CP2, 2007b. v.2, p.53-68.

MARTINS FILHO, M.V.; LICCIOTTI, T.T.; PEREIRA, G.T.; MARQUES JÚNIOR, J.; SANCHEZ, R.B. Perdas de solo e nutrientes por erosão num argissolo com resíduos vegetais de cana-de-açúcar. Engenharia Agrícola, Jaboticabal, v.29, n.1, p.8-18, 2009.

OLIVEIRA, F.P. de. Determinação da tolerância de perdas por erosão para as principais ordens de solos do Estado da Paraíba. 2004. 92 f. Monografia (Trabalho de Graduação em Engenharia Agronômica) - Centro de Ciências Agrárias, Universidade Federal da Paraíba, Areia, 2004.

PEREIRA, M.W.G.; ARÊDES, A.F.; TEIXEIRA, E.C. Avaliação econômica do cultivo de trigo dos Estados do Rio Grande do Sul e Paraná. Revista de Economia e Agronegócio, Viçosa-MG, v.5, n.4, p.591-610, 2007.

PUGLIESI, A.C.V. Valoração econômica pelo método custo de reposição do efeito da erosão em sistemas de produção agrícola. 2007. 158 f. Dissertação (Mestrado) - Universidade Estadual de Campinas, Faculdade de Engenharia Agrícola, Campinas, 2007.

SANCHEZ, R.B. Zonas de manejo caracterizadas por meio de pedoformas em área sob cultivo de cana-de-açúcar. 2003. 140 f. Dissertação. (Mestrado em Ciência do Solo) - Universidade Estadual Paulista, Faculdade de Ciências Agrárias e Veterinárias, Jaboticabal, 2003.

SERRA, E.A. Expectativa e risco de erosão dos solos da FCAV/UNESP - Jaboticabal (SP). 2004. 75 f. Monografia (Trabalho de Graduação em Zootecnia) - Universidade Estadual Paulista, Faculdade de Ciências Agrárias e Veterinárias, Jaboticabal, 2004. 
SOUZA, Z.M.; MARTINS FILHO, M.V.; MARQUES JÚNIOR, J.; PEREIRA, G.T. Variabilidade de fatores de erosão em Latossolo Vermelho eutroférrico sob cultivo de cana-de-açúcar.

Engenharia Agrícola, Jaboticabal, v.25, n.1, p.105-114, 2005.

STATSOFT. Statistica: Quick reference. Tulsa: StatSoft, 1994. 148 p.

TORQUATO, S.A.; MARTINS, R.; RAMOS, F.S. Cana-de-açúcar no Estado de São Paulo: eficiência econômica das regiões novas e tradicionais de produção. Informações Econômicas, São Paulo, v.39, n.5, p.92-99, 2009.

UDOP. UNIÃO DOS PRODUTORES DE BIOENERGIA. Ranking dos estados produtores, Brasil - cana-de-açúcar. 2007. Disponível em: <http://docs.google.com/gview?a=v\&q=cache: DQChBzpOv9IJ:www.udop.com. Acesso em: 18 jun. 2009.

WALTON, R.S.; VOLKER, R.E.; BRISTOW, K.L.; SMETTEM, K.R.J. Experimental examination of solute transport by surface runoff from low-angle slopes. Journal of Hydrology, Amsterdam, v.233, n.1-4, p.19-36, 2000.

WISCHMEIER, W.H.; JOHNSON, C.B.; CROSS, B.V. A soil erodibility nomograph for farmland and construction sites. Journal of Soil and Water Conservation, Ankeny, v.25, n.5, p.183-189, 1971. WISCHMEIER, W.H.; SMITH, D.D. Predicting rainfall erosion losses: a guide to conservation planning. Washington: U.S. Departament of Agriculture, 1978. 58 p. (Handbook, 5). 